\title{
Post-Vaccination Leptospiral Antibody Titers among Pet Dogs in Malaysia
}

\author{
Goh $\mathrm{SH}^{1,2},{\mathrm{Khor} \mathrm{KH}^{1 *}, \text { Lau SF}}^{1}$, Khairani-Bejo $\mathrm{S}^{1}$ and Sabri $\mathrm{AR}^{1,2}$ \\ ${ }^{1}$ Faculty of Veterinary Medicine, Universiti Putra Malaysia, 43400 Serdang, Selangor Darul Ehsan, Malaysia \\ ${ }^{2}$ Faculty of Veterinary Medicine, Universiti Malaysia Kelantan, 16100 Kota Bharu, Kelantan, Malaysia \\ *Corresponding author: khkhor@upm.edu.my
}

\begin{abstract}
\begin{tabular}{llll}
\hline Article History: 21-343 & Received: 25-Jun-21 & Revised: 27-Jul-21 & Accepted: 01-Aug-21
\end{tabular}
\section{ABSTRACT}

Vaccine immunity among Malaysian dogs with its diverse circulating serovars, is still debatable. The recommended vaccination protocol was implemented on a local level, but there was little local documentation of vaccine antibody titer production. This study evaluated the duration and magnitude of antibody titers before, during and after vaccination in both overtly healthy puppies and adult dogs. Puppies ( $n=20 ; 6-8$ weeks) and adult dogs ( $n=20 ; 1-5$ years old) were recruited. The dogs were vaccinated with a commercial quadrivalent vaccine (Icterohaemorrhagiae, Canicola, Grippotyphosa and Pomona) according to guidelines [World Small Animal Veterinary Association (WSAVA)]. Blood was sampled at pre- and post-vaccination up to one-year duration at intervals of 2, 4, 6, 8, 10, 12 weeks followed by 6,9,12 months. Serum was tested against the vaccine serovars using microscopic agglutination test (MAT) while whole blood for polymerase chain reaction (PCR). The antibody titer in puppies ranged between 1:50 to 1:200 was present for 6 months whereas the adults had higher titer of between 1:50 to 1:800 for a duration of one year. The antibody titers detected was the highest and persisted the longest for serovar Icterohaemorrhagiae followed by serovars Canicola, Grippotyphosa and Pomona. All dogs were PCR negative throughout the study period. Consideration should be taken when interpreting MAT results of clinical cases with presence of vaccine antibodies, requiring paired serum for better serodiagnosis. MAT remains a gold standard serological method for diagnosis and surveillance, current findings may become a basis of comparison allowing better interpretation and improved usability.
\end{abstract}

\section{Key words: Immunity, Leptospira, Canine, Vaccine, MAT.}

\section{INTRODUCTION}

Leptospirosis is a predominantly tropical zoonoses (Adler 2015). Canine leptospirosis are caused by pathogenic serovars belonging to the Leptospira interrogans species, however other species have also been reported (Ellis 2010). Serovars of canine importance include L. interrogans serovars Icterohaemorrhagiae, Canicola, Pomona, Bratislava and Copenhageni; $L$. borgpetersenii serovar Hardjo; and L. kirschneri serovar Grippotyphosa (Friedland et al. 2010; Grosenbaugh et al. 2018). Because of the high mortality rate in dogs with zoonotic implications, widespread vaccination was implemented to provide immune protection (Rentko et al. 1992). The cause-effect relationship between widespread vaccination and the decreased prevalence has been reported (Lee et al. 2014), however the impact of vaccination locally remains unclear.

The current local vaccination protocol was adopted from the Vaccine Guideline Group of World Small Animal Veterinary Association (WSAVA) which comprises of four serovars (Icterohaemorrhagiae, Canicola, Grippotyphosa and Pomona) (Day et al. 2016). In Malaysia, the seroprevalence of canine leptospirosis ranges from 3-50\% (Samsi et al. 2013; Khor et al. 2016; Lau et al. 2016, 2017; Goh et al. 2019) and other serovars have been insinuated to cause the disease despite a good vaccination practice locally. The variation in prevailing leptospiral serovars differs by geographical location ( Jimenez-Coello et al. 2008; Lavinsky et al. 2012; Roqueplo et al. 2014). Therefore, despite vaccination received, some dogs have been reported infected with leptospira (Kohn et al. 2010). Such reports are of expected as protection from the vaccination were serovars specific (Ko et al. 2009; Subathra et al. 2013). In recent years, incidence of the disease reported involved newer serovars such as L. kirschneri serovar Grippotyphosa, $L$. interrogans serovar Pomona, and L. interrogans serovar Bratislava (Goldstein et al. 2006). These newer serovars pose a problem for disease control because these serovars are not available in the vaccines, thus putting dogs at risk of infection if exposed.

Cite This Article as: Goh SH, Khor KH, Lau SF, Khairani-Bejo S and Sabri AR, 2022. Post-vaccination leptospiral antibody titers among pet dogs in Malaysia. International Journal of Veterinary Science 11(2): 151-158. https://doi.org/10.47278/journal.ijvs/2021.086 
Currently, most vaccines are chemically inactivated whole culture vaccines (Tilahun et al. 2013; Silveira et al. 2017). Despite the changes in antibody titers being well documented (Barr et al. 2005), some level of uncertainty remains as to whether similar responses occurred among dogs locally. Mixture of responses in post-vaccination MAT titers have been recorded, although findings indicate an antibody lifespan of 12 months (Andre-Fontaine et al. 2003; Klaasen et al. 2003). Some have reported a minor increase while others reported major rapid spikes in the antibody titer, especially during the first 12 to 16 weeks after the initial administration of the vaccine (AndreFontaine et al. 2003; Klaasen et al. 2003; Barr et al. 2005). With such variation, observing the antibodies titer changes post-vaccination in dogs locally becomes important as information obtained may guide MAT interpretation for diagnostic evaluation.

The current study documented the level of antibody titers throughout the period of one year post-vaccination and determined the duration and magnitude of vaccine antibody titer among private owned pet dogs maintained in their respective homes (Wilson et al. 2013). The level of antibody titers (pre- and post-vaccination) can be used as a reference or guide for MAT interpretation. Preliminary findings can be used as a reference guide for MAT interpretation and assist laboratory technicians to improve their serological interpretation allowing better disease management (Schreier et al. 2013).

\section{MATERIALS AND METHODS}

This study obtained ethical approval from the Institutional Animal Care and Use Committee (UPM/IACUC/AUP-R073/2017).

\section{Puppies and Adult Dogs}

Client-owned overtly healthy puppies and adult dogs were recruited. Enrolment criteria required for these puppies and adult dogs had a normal finding from physical examination and unremarkable results of the blood test (normal haematological and serum biochemistry parameters) and urinalysis. Puppy must be of aged between 6 to 8-week-old and had not received any vaccination. Adult dogs were between 1 to 8 -year-old upon presentation with an up-to-date annual vaccination record using the commercial quadrivalent vaccine (Icterohaemorrhagiae, Canicola, Grippotyphosa and Pomona). All the puppies and adult dogs must be free of leptospirosis (prior to vaccination, Day 0) based on serological and molecular testing, as described below. Information regarding the signalment and management of the dogs including any lineage history (if available) with regards to vaccination were noted. Consent was obtained from owners prior to recruitment of their dog in the study.

\section{Vaccination Protocol}

The vaccination regime used in this study was in accordance with WSAVA guidelines for the vaccination of dogs and cats (Day et al. 2016). A commercial quadrivalent vaccine (Icterohaemorrhagiae, Canicola, Grippotyphosa and Pomona) (USA) containing inactivated whole cell leptospiral bacterin was administered subcutaneously at the nape of their necks.
Puppies received 3 consecutive doses at monthly intervals to complete the vaccination protocol whereas adult dogs were given a single injection as booster for annual vaccination. Both groups of dogs were maintained and monitored in their home environment.

\section{Blood Sampling}

For puppies, additional blood samples were collected fortnightly as the puppies received and completed the vaccination. Upon completion of the vaccination in both groups of dogs, blood was collected to monitor the leptospiral antibody titer for a period of a year. Each puppy and adult dog was gently restrained and approximately $3 \mathrm{~mL}$ of blood was collected via the cephalic venipuncture by a practicing veterinarian. The time points of blood collection were as follows; Day-0 (prior to vaccination), followed by 2-, 4-, 6-, 10-, and 16weeks post-vaccination and later 6-, 9-, and 12-months post-vaccination. Blood samples obtained were stored in plain and ethylenediaminetetraacetic acid (EDTA) vacutainer tubes, maintained in $4^{\circ} \mathrm{C}$ (chiller box) and immediately transported to the Bacteriology Laboratory of Faculty of Veterinary Medicine, Universiti Putra Malaysia. The blood samples were then centrifuged at $2130 \mathrm{G}$ for $10 \mathrm{~min}$, aliquoted into $1.5 \mathrm{~mL}$ Eppendorf tubes and stored $\left(-20^{\circ} \mathrm{C}\right)$ for further analysis.

\section{Microscopic Agglutination Test (MAT)}

All sera samples collected were tested for agglutinating antibodies against 10 serovars commonly associated with dogs which included vaccine (Icterohaemorrhagiae, Canicola, Grippotyphosa, Pomona) and non-vaccine (Australis, Autumnalis, Javanica, Bataviae, Lai, Ballum) serovars (Sykes et al. 2011; Schuller et al. 2015). Antigens were obtained from Leptospirosis Reference Laboratory, Queensland Health, Queensland, Australia. End titers for each sample were determined by assay of sample serial dilutions started from 1:50 to 1:51200. A dilution point was considered seroconverted if there was at least $<50 \%$ free leptospires and $>50 \%$ agglutination when compared to the positive control (hyperimmune serum) and negative control (antigen only). Results were tabulated and the highest level of antibody titer for each of the serovars tested was reported. In this study, an antibody titer of $\geq 1: 50$ was considered evidence of antibodies towards the serovars tested. The MAT test was performed in duplicate and recorded in a single laboratory avoiding laboratory bias (André-Fontaine 2016).

\section{Polymerase Chain Reaction (PCR)}

Whole blood samples collected were analysed using conventional PCR. Two 16S rRNA primers (5'GAACTGAGACACGGTCCAT-3' and 5' GCCTCAGCGTCAGTTTTAGG-3') and two LipL32 primers (5'ATCTCCGTTGCACTCTTTGC3' and 5'ACCATCATCATCATCGTCCA3') were used for molecular detection of Leptospira spp. Prior to recruitment, the dogs were tested to ensure free of leptospirosis. During the sampling period, blood sample collected of dogs with agglutinating antibodies were tested to ensure that antibody production was not linked to potential natural exposure (Midence et al. 2012). 


\section{Statistical Analysis}

Data collected were descriptively analysed using IBM SPSS version 26 (IBM, USA). The median values of the antibody titers were reported for each sampling time points as the data was not normally distributed. The numbers of dogs were presented in percentage (\%) in the graphs. Friedman Test was also carried out to determine the significance in the antibody titer changes as well as the trend titer changes across the sampling period. The significant level was accepted at $\mathrm{P} \leq 0.05$ (Castro-Herrera et al. 2018; Li et al. 2021).

\section{RESULTS}

\section{Puppy and Adult Dog Group}

A total of 20 puppies with a median age of 2 months (ranged between 2-4 months) consisted of 6 females and 14 males were recruited. Twenty adult dogs (median age of 4 years old, ranged of between 2-8 years) consisted of 9 females and 11 males were identified. Prior to vaccination (at Day 0), both groups of dogs were seronegative towards all 10 serovars (based on MAT) and negative on PCR. All the dogs were not observed to have any adverse reaction towards the vaccine administered. During the 12 months period, all puppies and adult dogs were physically examined and observed overtly healthy. These dogs were also found seronegative for the non-vaccinal serovars and negative for PCR throughout the 12 months the sampling period.

Majority of dogs/puppies were local dogs except for a few pedigree animals (Rottweiler, German Shepherd Dog, Golden Retriever, Labrador Retriever, Poodle, Chihuahua, Neapolitan and Siberian Husky). All the local dogs/puppies recruited in this study were adopted dogs with no known history of vaccinated dams or sires. The dogs/puppies with known history of vaccinated dams/sires were those of pedigree descent. The vaccination record/vaccination card presented during physical examination was referred to determine the vaccination history of the adult dogs recruited. All the dogs were housed indoors with limited outdoor exposure except for the occasional walks and fed on dry commercial diets.

\section{Monitoring of Antibody Titer Response during Vaccination Period for Puppies}

The antibody titer response towards the vaccinal serovars was monitored for 3 months. After receiving the first dose of vaccine, $80 \%(n=16 / 20)$ of puppies had a median antibody titer of 1:100 towards Icterohaemorrhagiae at week-2 (Fig. 1) but reduced to 1:50 at week-4. After receiving the second injection (booster), antibodies titers were increased (1:200) but were short lived with no further increase (median antibody titers of 1:100) despite third injection administered. The median antibody titer documented ranged between 1:50 to 1:200 and the highest antibodies titer recorded was 1:800 from three puppies at week 6 . As for serovar Canicola, majority of puppies $(85 \% ; n=17 / 20)$ developed a median antibody titer response of 1:50 postvaccination (week-2) whereas some of these puppies remained seronegative. Only 11 puppies $(55 \%)$ had antibodies at week-4 post-vaccination but after second vaccination (booster) was given, a 100\% of the puppies had median antibodies titer ranged between 1: 50 to 1:100 which persisted until the completion of vaccination. During the vaccination period, one puppy $(5 \% ; n=1 / 20)$ showed the highest titer at 1:800 at week 6 .

The antibody titer detected towards serovar Grippotyphosa and Pomona were in similar trend, with low levels detected. After the first dose of vaccine, only 8 puppies $(45 \% ; n=8 / 20)$ had antibodies titers of $>1: 50$ towards serovar Grippotyphosa and 2 puppies (10\%; $\mathrm{n}=2 / 20$ ) for serovar Pomona, respectively. The number of puppies reduced to 5 (25\%) for serovar Grippotyphosa and none for serovar Pomona by week-4 with a median antibody titer response towards both serovars were $\leq 1: 50$. After the second dose of vaccine, $100 \%$ of the puppies seroconverted for both serovars which lasted until the third vaccination at median antibody titer response of 1:50. The median antibody titer response appeared undectactable despite the third dose of vaccine. The highest titer noted for serovar Grippotyphosa was at 1:200 in one puppy (5\%) and 1:100 in two puppies (10\%) for serovar Pomona that was observed at week- 6 , after the second vaccination.

\section{Magnitude and Duration of Antibody Titer Response Post-Vaccination (Completed 3 Doses) for Puppies \\ Following vaccination completion, $100 \%$ of the} puppies had a median antibody titer of 1:100 towards serovar Icterohaemorrhagiae at week-2 post-vaccination but the titers decreased to 1:50 (week-4) and persisted until week-10 (Fig. 2). The highest antibodies titer (1:200) was observed in one puppy (5\%) at week 2 . It was observed that starting from week 6 , the puppies started to have absence of antibodies. At week-12, only $40 \%$ $(n=8 / 20)$ of the puppies had detectable antibodies titer and the number of puppies gradual reduced by month- 9 with only one puppy (5\%) having antibodies. At the end of one year, none of the puppies had antibodies. The median antibody titers across the time points were significantly different $\left(\chi^{2} \quad(13, \mathrm{n}=20)=208.81, \mathrm{P}<0.001\right)$. Median values showed downward trend in median antibody titer from week-2 $(\mathrm{Md}=9=11.48)$ to month-12 $(\mathrm{Md}=3.30)$.

As for serovar Canicola, it was observed that only 16 out of 20 puppies (Fig. 3) had antibodies and the numbers of puppy gradually decreased over time. Only five puppies $(25 \%)$ had detectable antibodies by week-10 and left with one puppy (5\%) by month-6. The median antibody titer for puppies peaked at 1:50 with the highest single titer at 1:200 observed in a puppy (5\%) at week-2. The median antibody titers across the sampling period were significantly different $(\chi 2 \quad(13, \mathrm{n}=20)=189.35$, $\mathrm{P}<0.001)$. Median values exhibited decrease in median antibody titer from week-2 $(\mathrm{Md}=10.00)$ to month-12 $(\mathrm{Md}=4.60)$.

Antibodies of serovar Grippotyphosa was detected in $75 \%(n=15 / 20)$ of the puppies at week-2 post-vaccination with highest titer detected at 1:100, present in one puppy $(5 \%)$ at week-2 (Fig. 4). The percentage of puppies gradually decreased by week-12 and left with only 4 puppies $(20 \%)$ having antibodies. By month-6 onwards, all the puppies had absence of detectable antibodies. Upon completion of the vaccination program, the mean antibodies titer (1:50) remained until week-4 and further decreased to $\leq 1: 50$ by week- 6 . The median antibody titers 
across the time points were significantly different $(\chi 2(13$, $\mathrm{n}=20)=180.40, \mathrm{P}<0.001)$. There were decreasing median values with regards to median antibody titer from week-2 $(\mathrm{Md}=9.98)$ to month-12 $(\mathrm{Md}=4.88)$.

Only 11 puppies $(55 \%)$ had detectable antibodies for serovar Pomona at week-2 post-vaccination with median titer of 1:50 (Fig. 5) and by week-10, only $10 \%(n=2 / 20)$ of puppies still had antibodies. The highest titer after vaccination completion was 1:50 in 11 puppies (55\%) at week 2. By week-12, all puppies antibodies were $\leq 1: 50$ till the end of the monitoring period. The median antibody

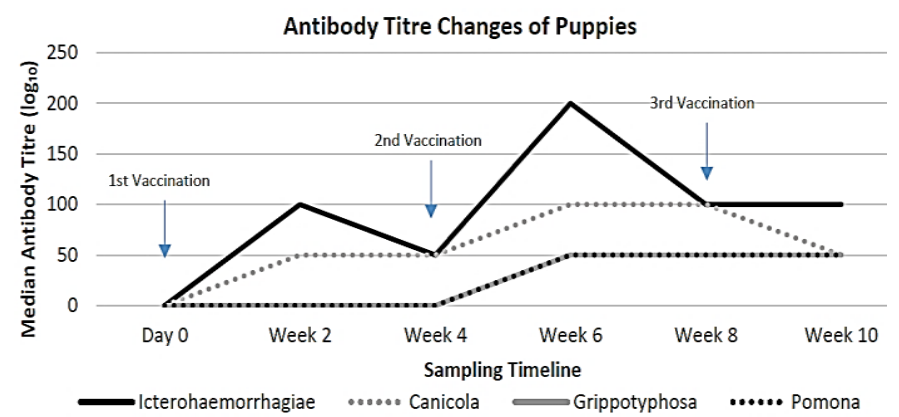

Fig. 1: Antibody titer changes of puppies during vaccination for all serovars.

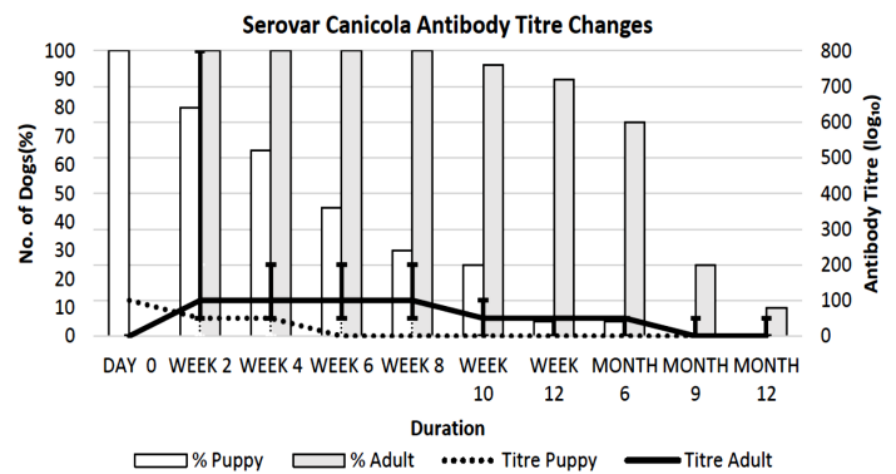

Fig. 3: Antibody titer changes of puppies and adult dogs for serovar Canicola over a period of one year with respective percentages of puppies and dogs with titers $>1: 50$. titers between the sampling points were significantly different $(\chi 2(13, \mathrm{n}=20)=165.28, \mathrm{P}<0.001)$. Median values showed decreasing trend in median antibody titer from week-2 $(\mathrm{Md}=9.53)$ to month-12 $(\mathrm{Md}=5.70)$.

\section{Magnitude and Duration of Antibody Titer Response Post- Vaccination (a Single Annual Booster) for Adult Dogs}

Following the annual booster injection, $100 \%$ of the adult dogs had antibody titer detected towards serovar Icterohaemorrhagiae up to period of 12 weeks (Fig. 2). The median antibody titer for dogs peaked at 1:200 which

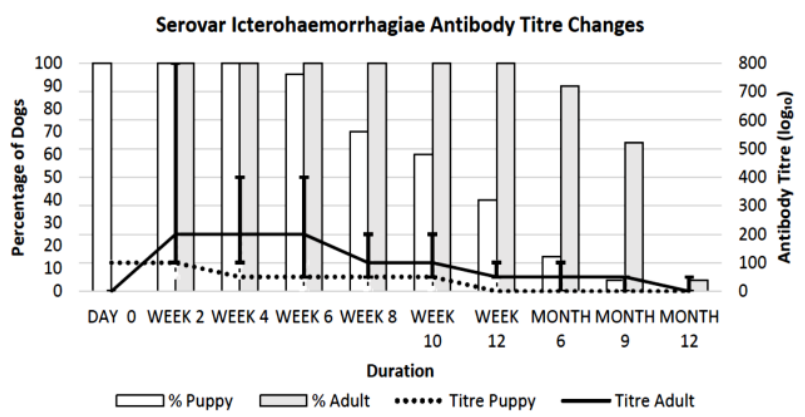

Fig. 2: Antibody titer changes of puppies and adult dogs for serovar Icterhaemorrhagiae over a period of one year with respective percentages of puppies and dogs with titers $>1: 50$.

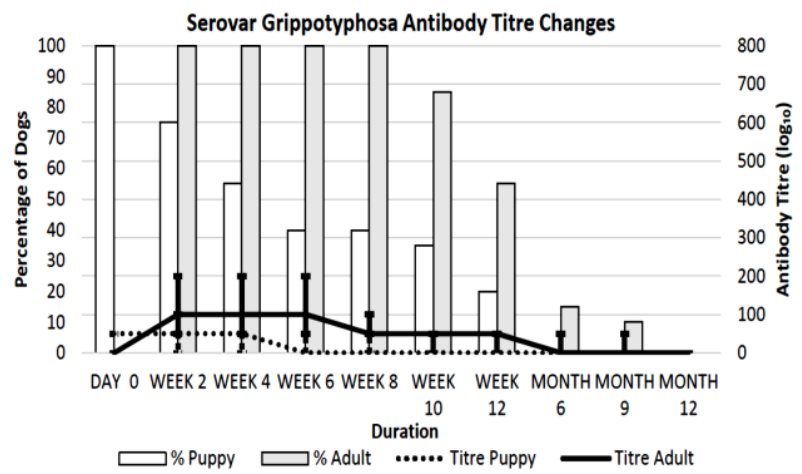

Fig. 4: Antibody titer changes of puppies and adult dogs for serovar Grippotyphosa over a period of one year with respective percentages of puppies and dogs with titers $>1: 50$.

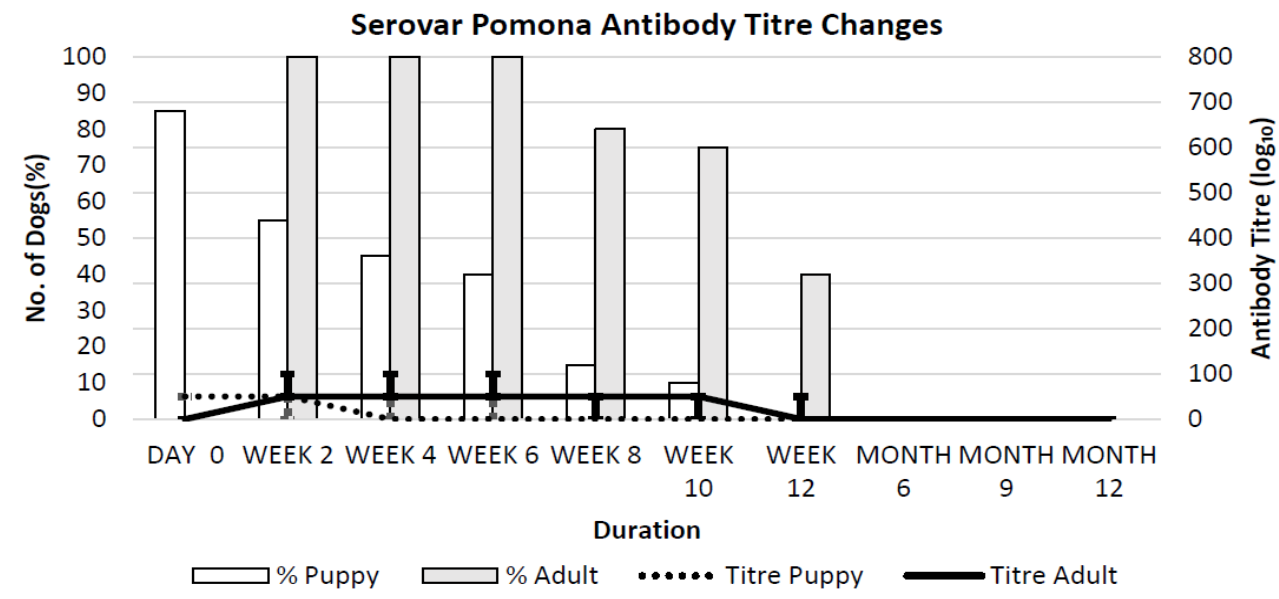

Fig. 5: Antibody titer changes of puppies and adult dogs for serovar Pomona over a period of one year with respective percentages of puppies and dogs with titers $>1: 50$. 
lasted for a month, dropped to 1:100 (Week-6) and further decreased to $1: 50$ by week-12. At month- 6 postvaccination, majority of the adult dogs $(90 \%)$ still had antibody titers but the number of dogs was decreased in month-9 (65\%; $(n=13 / 20))$ and left with one dogs with detectable antibody at month-12. The highest antibody titer in adult dogs (1:800) was recorded at week-2 in two dogs $(10 \%)$. These two dogs were negative based on PCR. The median antibody titers across the time points were significantly different $(\chi 2(9, \mathrm{n}=20)=164.72, \mathrm{P}<0.001)$. Median values showed decreasing trend in median antibody titer from week-2 $(\mathrm{Md}=9.23)$ to month-12 $(\mathrm{Md}=1.80)$.

Similarly, all the adult dogs had antibodies titers towards serovar Canicola with peak median antibody titer of 1:100 up to week-8 (Fig. 3). In adult dogs, the antibodies titers were gradually decreased over time and by month 9 , only 5 dogs $(25 \%)$ had detectable antibodies titers. Eventually, one adult dog (5\%) had persistent antibodies (1:50) until end of one year. The highest antibody titer recorded among the adult dogs was 1:800 detected at week-2 post-vaccination with negative PCR findings. The median antibody titers across the time points were significantly different $(\chi 2 \quad(9, \mathrm{n}=20)=159.04$, $\mathrm{P}<0.001)$. Median values showed decreasing trend in median antibody titer from week-2 $(\mathrm{Md}=9.10)$ to month$12(\mathrm{Md}=2.25)$.

All the adult dogs had antibodies titers towards serovar Grippotyphosa (Fig. 4) with a median antibody titer of 1:100. However, the level of the antibodies observed lasted up to week- 8 and further decreased up to month-9 post-vaccination (10\%) and no dogs had antibodies titers by month-12. The highest antibody titer recorded (1:200) was noted in nine dogs $(45 \%)$ at week-2. The median antibody titers between the various sampling times were significantly different $(\chi 2(9, n=20)=155.25$, $\mathrm{P}<0.001)$. Median values showed decreasing trend in median antibody titer from week-2 $(\mathrm{Md}=9.03)$ to month$12(\mathrm{Md}=2.65)$.

As for serovar Pomona, all adult dogs (100\%) had low antibody levels (1:50) (Fig. 5) up to week-6 postvaccination. However, by week- 8 , only $80 \%(n=16 / 20)$ of dogs had detectable antibodies with the number of dogs decrease until month-3. By month 6, none of the dogs had measurable antibody titers. Serovar Pomona recorded a titer of 1:100 as the highest titer in only ten dogs $(50 \%)$ which was achieved at week 2 . The median antibody titers across the time points were significantly different ( $\chi 2$ (9, $\mathrm{n}=20)=149.67, \quad \mathrm{P}<0.001)$. Median values showed decreasing trend in median antibody titer from week-2 $(\mathrm{Md}=8.78)$ to month-12 $(\mathrm{Md}=3.03)$.

\section{DISCUSSION}

The serological diagnosis of leptospirosis based on MAT interpretation alone becomes complicated if the dog has been vaccinated. Despite MAT being considered suitable for diagnosing acute leptospiral infections, it remains a limited tool in assessing the immunogenicity of leptospira vaccines (Andre-Fontaine et al. 2003). MAT remains as a commonly used test in many parts of the world as a screening tool especially in acute cases
(Klaasen and Adler 2015). The current documentation of antibody titers (magnitude and duration) will hopefully provide a basis of comparison allowing for better MAT interpretation. In the long run, this improves the usability of MAT both as a screening and diagnostic tool, especially locally. Many veterinarians still rely on antibody testing alone in conjunction with clinical symptoms to diagnose cases.

Diagnosis becomes challenging as temporal titer changes occur post-vaccination in addition to inability of MAT to differentiate vaccine and infection antibodies especially in recently vaccinated dog (Midence et al. 2012). Paired serum (3-4 weeks apart) is recommended as exponential titer increase occur during an infection while post-vaccination titers have usually low transient increases (Barr et al. 2005). Despite, MAT still being suited for diagnosing recent leptospirosis, findings suggests that careful assessment of antibody titers in association with the vaccination history of a patient that is suspected of having clinical leptospirosis is needed as higher titers during the early stages of vaccinations may mask true infection (Klaasen and Adler 2015). The sensitivity of MAT is very much dependent on the test method and the subjective readout by a technician (Cariou et al. 2020) which is improved by the built in positive and negative controls to mitigate error (Barr et al. 2005).

In the current group of puppies, the median antibody titer was highest at 1:100 (Icterohaemorrhagiae) followed by 1:50 (remaining serovars), as similarly reported previously (Minke et al. 2009). The peaking and decline of median antibody titer seen after second vaccination (Fig. 5) was similarly described by Schreiber (2012). The longest duration of antibodies post-vaccination in puppies was up till 9 months (Icterohaemorrhagiae), followed by 6 months (Canicola and Grippotyphosa) and 10 weeks (Pomona). In previous studies, a longer duration was observed for serovar Icterohaemorrhagiae and Canicola (present between 12-14 months) (Minke et al. 2009; Schreiber et al. 2012). A duration of 7 months (Grosenbaugh et al. 2018) and 13 months (Bouvet et al. 2016) was reported seen for serovar Grippotyphosa and the duration was slightly shorter in comparison of 16 weeks for serovar Pomona (Barr et al. 2005). The possible reason behind these differences could be related to the individual immunocompetency of the recruited puppies as the different ages and breed could have an impact on the immune response. Although, all the puppies were kept indoors and fed commercial diets, but these puppies were housed at different locations under different household conditions which could not be controlled and may led to potential enhancement or encumbrance of immune response. In earlier studies, animals were housed in a controlled environment which might have allowed a better immune response, but however does not reflect the actual scenarios of pet dogs. A longer duration could be resulting from absence of past sensitisation of the pristine immune system in specific pathogen free (SPF) animals producing strong immune response (Wilson et al. 2013). Results in this study were in agreement as naïve puppies failed to develop antibodies titers $\geq 1: 100$ even after booster vaccination (Barr et al. 2005). MAT titer $\geq 1: 100$ could indicate infection but was not likely for the dogs in this study, as dogs were negative based on PCR for the entire 
one year as monitored. The difference in vaccine types used could be another reason as inactivated vaccines have been shown to produce poor antibody responses (Klaasen et al. 2003; Schreiber et al. 2005). It is common for low antibodies titers to be detected among newly vaccinated animals (Andre-Fontaine et al. 2003; Fraga et al. 2011). The re-sensitise or booster effect of the second vaccine dose given within short intervals (Schultz et al. 2010) may allow a peak and a decline in antibody titers and this could be related to immunocompetency of the puppies being initially naïve (Wilson et al. 2013).

The median antibody titers in adult dogs peaked at 1:200 (Icterohaemorrhagiae) followed by 1:100 (Canicola and Grippotyphosa) and 1:50 (Pomona). In general, the level of antibodies was low in comparison with published report (Icterohaemorrhagiae titer at 1:400 (Barr et al. 2005), Canicola titers ranged to $\leq 1: 6400$ (Martin et al. 2014) and Pomona at 1:800 (Barr et al. 2005). Grippotyphosa titers was similar as in this study at 1:100 (Grosenbaugh et al. 2018). In general, a longer duration in adult dogs was observed compared to puppies. Antibodies lasted up to one year (Icterohaemorrhagiae and Canicola) followed by 9 months (Grippotyphosa) and 3 months (Pomona). Findings were similar to previous reports for Icterohaemorrhagiae (Wilson et al. 2013) and Canicola (Martin et al. 2014). The duration for Grippotyphosa antibodies was slightly longer than recent accounts of 7 months (Grosenbaugh et al. 2018). Duration for Pomona antibody was similar to past duration of 4 months (Martin et al. 2014). Higher titers with longer persistence among adults dogs were likely from past sensitisations (vaccination) (Day et al. 2014; Martin et al. 2014). The shorter Pomona antibody lifespan may be explained by the privately owned dogs (non-SPF) being managed differently and possibly being less immunogenic compared to SPF animals (Grosenbaugh et al. 2018). Due to the possibility that other factors such as natural exposure or immune competency potentially brought on by breed differences affecting the individual immuneresponse, comparison between vaccines was not attempted (Martin et al. 2014). The higher cut-off titers (1:100) used in past studies could have led to variations between studies. In certain older studies, adult dogs were given two vaccine doses (Martin et al. 2014) which could have provided a booster effect accounting for the higher titer (Schreiber et al. 2012).

The presence of antibody titers does not always indicate the animal's immune status. Several studies have found no link between vaccine immunity and MAT titers (Steger-Lieb et al. 1999; Klaasen et al. 2003; Barr et al. 2005; Minke et al. 2009; Schreiber et al. 2012; Wilson et al. 2013). Dogs with low $(\leq 1: 80)$ and short-lived (1-4 months) titers had allowed the dogs to be protected from leptospiremia and a renal carriage one year after vaccination (Schreiber et al. 2012), while other clientowned dogs developed clinical leptospirosis despite vaccinated (Tangeman et al. 2013). Such contradictions could be related to MAT limitations in measuring low post-vaccination titers (Martin et al. 2014). However, MAT titers somewhat suggest a degree of immunity as vaccinated dogs were known to produce weaker MAT response post-challenge than unvaccinated dogs (Klaasen et al. 2003).
The lack of correlation between immunity and MAT titers could be brought on by cross-reaction. In this study, cross-reaction was not evident but has been reported that cross reactions occur both during natural infection and vaccination (Barr et al. 2005). It was found that dogs vaccinated against Grippotyphosa and Pomona crossreacted towards serovar Autumnalis (Barr et al. 2005). This could be resulted either from contamination of the MAT antigen, contamination of the vaccine itself or nonserovar specific response of the vaccine detected by MAT. In general, a particular strain of a pathogenic Leptospira spp. can be placed in a single serovar belonging to a single serogroup. This may not be the case for serum antibodies, which have frequently shown cross-reactions to multiple serogroups, making MAT results poor predictors of serogroup (Blanco et al. 2016; AndréFontaine et al. 2018). Despite inconsistencies, some have noted correlations between highest MAT titers for a particular serogroup to the infecting serogroup in naive dogs regardless of the serovar detected with lower titers considered cross-reaction (Houwers et al. 2011; Blanco et al. 2016). Serum from the young naïve puppies failed to exhibit cross-reaction while those older previously sensitized dogs showed diverse cross-reactivity which could be an indication that frequent vaccination promotes cross-protection benefiting the animal (Schultz et al. 2010).

Diagnosis of leptospirosis is challenging, requiring crucial laboratory support. In spite of the availability of less tedious serological tests such as enzyme-linked immunosorbent assay (ELISA), MAT still remains the reference test for the serodiagnosis of leptospirosis both in humans and animals (Schreier et al. 2013). MAT remains relevant due to its ability to determine the infecting serovar/serogroup. The sensitivity of the testing is relatively high but is dependent on the panel of serovars used during testing which should include locally prevalent serovars and local isolates (Day et al. 2016). This is further improved by paired sera sampling 2-4 weeks apart, where a 4-fold titer increase is usually consistent with an infection (Barr et al. 2005; André-Fontaine 2016). With the presence of vaccination, MAT interpretation becomes challenging as there is lacking local data on antibodies titers post-vaccination.

\section{Conclusion}

The level of antibodies titer in client-owner dogs and puppies post-vaccination were low and lasted only for limited duration. This information will hopefully aid in disease management by improving serological testing both in diagnosis and surveillance. As MAT titers are used to demonstrate a humoral response to the vaccinal antigens, it is likely that this test will continue to be used to examine such responses to future vaccines. Despite the current absence of cross-reaction, additional studies with longer duration, larger sample size or challenging similar group of dogs with leptospira infection may be beneficial. The presence of these circulating antibodies complicates diagnosis of leptospirosis through the occurrence of false positives in MAT testing. Nevertheless, current vaccine recipient's immune response observation may assist and improve interpretation of MAT when comparing vaccine titers in different group of dogs which becomes a basis of reference. 


\section{Acknowledgement}

The authors would like to acknowledge the contributions of those involved directly and indirectly with this research. Heartfelt gratitude also goes to the owners of the dogs for their willingness to participate in the study. The authors would also like to thank the staff from the Bacteriology Laboratory of the Faculty of Veterinary Medicine, Universiti Putra Malaysia, for their technical assistance. This research was funded by Universiti Putra Malaysia under the Inisiatif Putra Siswazah (IPS) Research Grant (GP-IPS/2017/9577100) and by Ministry of Higher Education (MOHE), Malaysia under the Fundamental Research Grant Scheme (FRGS); FRGS/1/2016/SKK02/UPM/02/1/5524930.

\section{Author's Contribution}

GSH, KKH, LSF, SKB designed and conceptualized the study, interpreted the results, and arranged the publication draft. GSH, KKH, LSF, SKB, SAR were involved in the project administration through the collection of data and contributed to paper preparation. GSH, KKH, LSF, SKB took part in funding acquisition and critically editing this manuscript. All authors reviewed the manuscript individually and approved the final manuscript.

\section{REFERENCES}

Adler B, 2015. History of Leptospirosis and Leptospira. In: Adler B (eds) Leptospira and Leptospirosis. Current Topics in Microbiology and Immunology, vol 387. Springer, Berlin, Heidelberg. https://doi.org/10.1007/ 978-3-662-45059-8_1

André-Fontaine G and Triger L, 2018. MAT cross-reactions or vaccine cross-protection: retrospective study of 863 leptospirosis canine cases. Heliyon 4: e00869. https://doi.org/10.1016/j.heliyon.2018.e00869

André-Fontaine G, 2016. Leptospirosis in domestic animals in France: Serological results from 1988 to 2007. OIE Revue Scientifique et Technique 35: 913-923. https://doi.org/ 10.20506/rst.35.3.2579

Andre-Fontaine G, Branger C, Gray AW and Klaasen HLBM, 2003. Comparison of the efficacy of three commercial bacterins in preventing canine leptospirosis. Veterinary Record 2: 165-169.

Barr SC, McDonough PL, Scipioni-Ball RL and Starr JK, 2005. Serologic responses of dogs given a commercial vaccine against Leptospira interrogans serovar pomona and Leptospira kirschneri serovar grippotyphosa. American Journal of Veterinary Research 66: 1780-1784. https://doi.org/10.2460/ajvr.2005.66.1780

Blanco RM, dos Santos LF, Galloway RL and Romero EC, 2016. Is the microagglutination test (MAT) good for predicting the infecting serogroup for leptospirosis in Brazil? Comparative Immunology, Microbiology and Infectious Diseases 44: 34-36. https://doi.org/10.1016/ j.cimid.2015.12.003

Bouvet J, Cariou C, Valfort W, Villard S, Hilaire F, Oberli F, Cupillard L and Guigal PM, 2016. Efficacy of a multivalent DAPPi-Lmulti canine vaccine against mortality, clinical signs, infection, bacterial excretion, renal carriage and renal lesions caused by Leptospira experimental challenges. Vaccine Reports 6: 23-28. https://doi.org/10.1016/j. vacrep.2016.07.003

Cariou C, Herbet G, Ripart P, Martin-Cagnon N, Bouvet J, Schneider M, Guiot AL and Cupillard L, 2020. Development of antibody ELISA specific of Leptospira interrogans serovar Grippotyphosa, Canicola, and Icterohaemorrhagiae to monitor vaccine immunogenicity. Veterinary Immunology and Immunopathology 209: 109960. https://doi.org/10.1016/j.vetimm.2019.109960

Castro-Herrera V, Lown M, Lewith G, Miles EA and Calder PC, 2018. Influence of delayed sample processing on blood immune cell phenotypes, immune cell responses and serum anti-influenza vaccine antibody titers. Journal of Immunological Methods 458: 8-14. https://doi.org/ 10.1016/j.jim.2018.03.012

Day MJ and Schultz RD, 2014. Veterinary Immunology: Principles and Practice. Retrieved from https://books.google.se/books?id=FHvOBQAAQBAJ

Day MJ, Horzinek MC, Schultz RD and Squires RA, 2016. WSAVA Guidelines for the vaccination of dogs and cats Journal of Small Animal Practice 57: E1-E45. https://doi.org/10.1111/jsap.2_12431

Ellis WA, 2010. Control of canine leptospirosis in Europe: time for a change? Veterinary Record 167: 602-605. https://doi.org/10.1136/vr.c4965

Fraga TR, Barbosa AS and Isaac L, 2011. Leptospirosis: Aspects of innate immunity, immunopathogenesis and immune evasion from the complement system. Scandinavian Journal of Immunology 73: 408-419. https://doi.org/10.1111/j. 1365-3083.2010.02505.x

Friedland JS and Warrell DA, 2010. The Jarisch-Herxheimer reaction in leptospirosis: possible pathogenesis and review. Reviews of Infectious Diseases 13: 207-210. Retrieved from http://www.ncbi.nlm.nih.gov/pubmed/2041950

Goh SH, Ismail R, Lau SF, Megat Abdul Rani PA, Mohd Mohidin TB, Daud F, Bahaman AR, Khairani-Bejo S, Radzi R and Khor KH, 2019. Risk Factors and Prediction of Leptospiral Seropositivity Among Dogs and Dog Handlers in Malaysia. International Journal of Environmental Research and Public Health 16: 1499. https://doi.org/10.3390/ijerph16091499

Goldstein RE, Lin RC, Langston CE, Scrivani P V, Erb HN and Barr SC, 2006. Influence of infecting serogroup on clinical features of leptospirosis in dogs. Journal of Veterinary Internal Medicine / American College of Veterinary Internal Medicine 20: 489-494. https://doi.org/10.1111/ j.1939-1676.2006.tb02886.x

Grosenbaugh DA and Pardo MC, 2018. Fifteen-month duration of immunity for the serovar Grippotyphosa fraction of a tetravalent canine leptospirosis vaccine. Veterinary Record 182: 665. https://doi.org/10.1136/vr.104694

Houwers DJ, Goris MGA, Abdoel T, Kas JA, Knobbe SS, van Dongen AM, Westerduin FE, Klein WR and Hartskeerl RA, 2011. Agglutinating antibodies against pathogenic Leptospira in healthy dogs and horses indicate common exposure and regular occurrence of subclinical infections. Veterinary Microbiology 148: 449-51. https://doi.org/ 10.1016/j.vetmic.2010.08.020

Jimenez-Coello M, Vado-Solis I, Cárdenas-Marrufo MF, Rodríguez-Buenfil JC and Ortega-Pacheco A, 2008. Serological survey of canine leptospirosis in the tropics of Yucatan Mexico using two different tests. Acta Tropica 106: 22-26.

Khor KH, Tan WX, Lau SF, Mohd AR, Rozanaliza R, Siti KB and Abdul RB, 2016. Seroprevalence and molecular detection of leptospirosis from a dog shelter. Tropical Biomedicine 33: 276-284.

Klaasen HLMB, Molkenboer MJCH, Vrijenhoek MP and Kaashoek MJ, 2003. Duration of immunity in dogs vaccinated against leptospirosis with a bivalent inactivated vaccine. Veterinary Microbiology 95: 121-132. https://doi.org/10.1016/S0378-1135(03)00152-4

Klaasen HLMB and Adler B, 2015. Recent advances in canine leptospirosis: focus on vaccine development. Veterinary Medicine: Research and Reports 6: 245-260. 
https://doi.org/10.2147/VMRR.S59521

Ko AI, Goarant C and Picardeau M, 2009. Leptospira: The Dawn of the Molecular Genetics Era for an Emerging Zoonotic Pathogen. Nature Reviews Microbiology 7: 736747. https://doi.org/10.1038/nrmicro2208.Leptospira

Kohn B, Steinicke K, Arndt G, Gruber AD, Guerra B, Jansen A, Kaser-Hotz B, Klopfleisch R, Lotz F, Luge E and Nöckler $\mathrm{K}$, 2010. Pulmonary abnormalities in dogs with leptospirosis. Journal of Veterinary Internal Medicine 24: 1277-1282. https://doi.org/10.1111/j.1939-1676.2010.0585. $\underline{x}$

Lau SF, Low KN, Khor KH, Roslan MA, Bejo SK, Radzi R and Bahaman AR, 2016. Prevalence of leptospirosis in healthy dogs and dogs with kidney disease in kidney disease in Klang Valley, Malaysia. Tropical Biomedicine 33: 469475.

Lau SF, Wong JY, Khor KH, Roslan MA, Abdul Rahman MS, Bejo SK, Radzi R and Bahaman AR, 2017. Seroprevalence of leptospirosis in working dogs. Topics in Companion Animal Medicine 32: 121-125. https://doi.org/10.1053/j. tcam.2017.12.001

Lavinsky MO, Said RA, Strenzel GMR and Langoni H, 2012. Seroprevalence of anti-Leptospira spp. antibodies in dogs in Bahia, Brazil. Preventive Veterinary Medicine 106: 79-84. https://doi.org/10.1016/j.prevetmed.2012.03.015

Lee HS, Guptill L, Johnson AJ and Moore GE, 2014 Signalment changes in canine leptospirosis between 1970 and 2009. Journal of Veterinary Internal Medicine 28: 294299. https://doi.org/10.1111/jvim.12273

Li C, Zhang N, Zhou J, Leung W, Gober HJ, Huang Z, Pan X, Chen L, Guan L and Wang L, 2021. Variations in the antithyroid antibody titer during pregnancy and after delivery. Risk Management and Healthcare Policy 14: 847859. https://doi.org/10.2147/RMHP.S279975

Martin LER, Wiggans KT, Wennogle SA, Curtis K, Chandrashekar R and Lappin MR, 2014. Vaccineassociated leptospira antibodies in client-owned dogs. Journal of Veterinary Internal Medicine 28: 789-792. https://doi.org/10.1111/jvim.12337

Midence JN, Leutenegger CM, Chandler AM and Goldstein RE, 2012. Effects of recent Leptospira vaccination on whole blood real-time PCR testing in healthy client-owned dogs. Journal of Veterinary Internal Medicine 26: 149-152. https://doi.org/10.1111/j.1939-1676.2011.00852.x

Minke JM, Bey R, Tronel JP, Latour S, Colombet G, Yvorel J, Cariou C, Guiot AL, Cozette V and Guigal PM, 2009. Onset and duration of protective immunity against clinical disease and renal carriage in dogs provided by a bi-valent inactivated leptospirosis vaccine. Veterinary Microbiology 137: 137-145. https://doi.org/10.1016/j.vetmic.2008.12.021

Rentko VT, Clark N, Ross LA and Schelling SH, 1992. Canine leptospirosis. A retrospective study of 17 cases. Journal of Veterinary Internal Medicine 6: 235-244. https://doi.org/ 10.1111/j.1939-1676.1992.tb00345.x

Roqueplo C, Marié J, André-fontaine G, Kodjo A and Davoust B, 2014. Serological survey of canine leptospirosis in three countries of tropical Africa: Sudan, Gabon and Ivory Coast. Comparative Immunology, Microbiology and Infectious Diseases 38: 57-61. https://doi.org/10.1016/j.cimid.2014. $\underline{10.006}$
Samsi NS, Zainol A, Darus A, Zainun Z, Wang SAW, Zainal Z and Hashim MA, 2013. Serodiagnosis of leptospirosis in domestic animals and humans. Malaysian Journal of Veterinary Research 4: 21-26.

Schreiber P, Martin V, Grousson D, Sanquer A, Gueguen S and Lebreux B, 2012. One-year duration of immunity in dogs for leptospira interrogans serovar icterohaemorrhagiae after vaccination. International Journal of Applied Research in Veterinary Medicine 10: 305-310.

Schreiber R, Martin V, Najbar W, Sanquer A, Gueguen S and Lebreux B, 2005. Prevention of a Severe Disease by a Leptospira Vaccination With a Multivalent Vaccine. Revue De Medecine Veterinaire 156: 427-432. https://doi.org/ 10.1103/PhysRevA.39.5867

Schreier S, Doungchawee G, Chadsuthi S, Triampo D and Triampo W, 2013. Leptospirosis: Current situation and trends of specific laboratory tests. Expert Review of Clinical Immunology 9: 263-280. https://doi.org/10.1586/ eci. 12.110

Schuller S, Francey T, Hartmann K, Hugonnard M, Kohn B, Nally JE and Sykes J, 2015. European consensus statement on leptospirosis in dogs and cats. Journal of Small Animal Practice 56: 159-179. https://doi.org/10.1111/jsap.12328

Schultz RD, Thiel B, Mukhtar E, Sharp P and Larson LJ, 2010. Age and Long-term Protective Immunity in Dogs and Cats. Journal of Comparative Pathology 142: S102-S108. https://doi.org/10.1016/j.jcpa.2009.10.009

Silveira MM, Oliveira TL, Schuch RA, McBride AJA, Dellagostin OA and Hartwig DD, 2017. DNA vaccines against leptospirosis: A literature review. Vaccine. https://doi.org/10.1016/j.vaccine.2017.08.067

Steger-Lieb A, Gerber B, Nicolet J \& Gaschen F, 1999. Die Hundeleptospirose verliert nicht an Aktualität [An old disease with a new face: canine leptospirosis does not lose its relevance]. Schweiz Arch Tierheilkd 141: 499-507.

Subathra M, Senthilkumar TMAA and Ramadass P, 2013. Recombinant ompl1 protein as a diagnostic antigen for the detection of canine leptospirosis. Applied Biochemistry and Biotechnology 169: 431-437. https://doi.org/10.1007/ s12010-012-9973-4

Sykes JE, Hartmann K, Lunn KF, Moore GE, Stoddard RA and Goldstein RE, 2011. 2010 ACVIM Small animal consensus statement on leptospirosis: Diagnosis, epidemiology, treatment, and prevention. Journal of Veterinary Internal Medicine 25: 1-13. https://doi.org/10.1111/j.1939-1676. 2010.0654.X

Tangeman LE and Littman MP, 2013. Clinicopathologic and atypical features of naturally occurring leptospirosis in dogs: 51 cases (2000-2010). Journal of the American Veterinary Medical Association. https://doi.org/10.2460/ javma.243.9.1316

Tilahun Z, Reta D and Simenew K, 2013. Global epidemiological overview of leptospirosis. International Journal of Microbiological Research 4: 9-15. https://doi.org/10.5829/idosi.ijmr.2013.4.1.7134

Wilson S, Stirling C, Thomas A, King V, Plevová E, Chromá L, Siedek E, Illambas J, Salt J and Sture G, 2013. Duration of immunity of a multivalent (DHPPi/L4R) canine vaccine against four Leptospira serovars. Vaccine 31: 3126-3130. https://doi.org/10.1016/j.vaccine.2013.05.043 